\title{
Habits Drinking Ordinary Water Can Prevent Hypertension
}

\author{
Tati Suheti, Kuslan Sunandar \\ Nursing Department of Health Polytechnic Bandung, Bandung, Indonesia \\ Email: Kuslan_Sunandar@yahoo.com \\ Received 2 March 2016; accepted 15 May 2016; published 18 May 2016 \\ Copyright (C 2016 by authors and Scientific Research Publishing Inc. \\ This work is licensed under the Creative Commons Attribution International License (CC BY). \\ http://creativecommons.org/licenses/by/4.0/ \\ (c) (i) Open Access
}

\begin{abstract}
Hypertension, as the third cause of death, besides stroke and tuberculosis, amounts to 6.8 percent of the proportion of deaths at all ages in Indonesia. The prevalence of hypertension in Indonesia has reached 31.7 percent of the total adult population. Estimated, there are 76 percent of cases of hypertension in people who have not been diagnosed. Drinking enough ordinary water will help maximize the function of the body organs, in order to work optimally, so that the body metabolism will run well and normal. For smokers this amount shall be increased by half. The purpose of research was to know the effect of drinking water and other factors on the prevention of hypertension in working area Puskesmas Pasirkaliki Bandung. Design study was case control. The number of samples is 156 people, with a ratio of 1:1 (between cases and controls). Data were collected by interviewing. The bivariate analysis used chi square test, and multivariate analysis used logistic regression. The result of drinking enough ordinary water at least 6 cups a day contributes to prevent hypertension. For those who are still healthy, habit of drinking ordinary water is recommended at least 6 cups $(1500 \mathrm{ml})$ per day. But for people who already have hypertension, heart and kidney diseases should be adjusted to the excretion organ.
\end{abstract}

\section{Keywords}

Drank an Ordinary Water to Prevent Hypertension

\section{Background}

Hypertension is the third cause of death, in addition to stroke and tuberculosis. The number reached 6.8 per cent of the proportion of causes of death in all age groups in Indonesia. Prevalence of hypertension in Indonesia has reached 31.7 percent of the total adult population. Of the above amount is only about 0.4 percent of patients taking antihypertensive medication for treatment [1]. Allegedly, there are 76 percent of cases of hypertension in 
people who have not been diagnosed. Trend in hypertension cases in Indonesia is likely to continue to increase [2].

Approximately 7.6 million people in 2011 died prematurely because of hypertension. Over a third of deaths in developing countries related to hypertension. The amount is more than half the number of cases of patients with stroke caused by hypertension. Overall about 80 percent of it occurs in low and middle income people and more than half occur at the age of 45 - 69 years. In developing countries there occurred 25 million stroke deaths and 598,000 deaths due to hypertension [3].

In the United States hypertension affects about 65 million people and is also experienced by most people in other countries in the world. Because the disease usually strikes without signs, so often referred to as the "Silent Killer”. Increased blood pressure can occur because of stiffness and slowness of (resistance) of blood flow causes the heart to grow heavy burden that ultimately compensated by increased efforts heart pumping faster. Increased heart pumping efforts lead to increased blood pressure in the circulatory system, so the faster the work of the heart to pump blood will lead to greater blood pressure or high [4]. Prevention of risk of death or other complications of therapy is still needed because the rise in blood pressure is a risk of cardiovascular and kidney disease.

According to the observations during D3 nursing students practice in Puskesmas Pasirkaliki Bandung in May 2012, was obtained from 40 patients the number of people who suffer from hypertension, 15 (40\%) in patients aged between 35 - 60 years. When compared with other hypertensive diseases it was the second largest number after the ISPA. Some risk factors that can be changed include hypertension associated with lifestyle, such as smoking, eating/drinking, drinking, drinking coffee, lack of physical activity/exercise and stress conditions [3] [5].

Smoking habits especially for men in Indonesia since the eighties have become a public health concern because it can cause a variety of diseases that can be life threatening or fatal. Smoking is a major cause of cardiovascular disease and hypertension [6]. Many substances contained in cigarettes and tobacco are toxic to the body; these substances stimulate the nervous system to make vasoconstriction, or narrowing of blood vessels that stimulate the heart to work harder, and this is what makes the state of hypertension.

On the condition of obesity are various theories to explain the relatively new theory mengemukaan hypertension in obesity is influenced by the presence of leptin resistance in the kidneys which in turn lead to an increase in plasma volume effect on improving cardiac output resulted in an increase in blood pressure [7].

The relationship between stress and hypertension is estimated by the sympathetic nerve that can increase blood pressure intermittently. If prolonged stress can lead to persistent elevation of blood pressure. In animal experiments it proved that exposure to stress causes these animals to become hypertensive [8].

Physical activity helps with weight control. Aerobic quite like 30 - 45 minutes of brisk walking every day helps lower blood pressure directly. Regular exercise can control blood pressure [9].

An effort to prevent hypertension is to get used to drink two liters of pure water a day. Result of Acin (2010) in the Village Antapani Kulon shows that water therapy for 14 days in people with mild hypertension with systolic 130 - $140 \mathrm{mmHg}$ and $90 \mathrm{mmHg}$ diastolic blood pressure can reduce an average of $10 \mathrm{mmHg}$. Humans are naturally born into a world made of water [10]. The human body is largely composed of water. So do not let humans lack of water, because it can cause blood circulation not smooth. Eighty percent of the human body consists of water. Brain and blood are two important organs that have a moisture content above $80 \%$. The brain has a component of water by $90 \%$, while the blood has a water component of 95\% [11].

In the human body, water has several functions, among other things: help the digestive system and absorption until the disposal process, helping remove the remnants of the metabolism of the stomach and kidneys, regulates body temperature, and provide a "lubricant" on the joints and membranes in the body, blood is a "means of transportation” that distribute nutrients throughout the body's tissues and $92 \%$ of blood consists of water, which is released by the body fluids and saliva almost entirely composed of water and every day of the digestive system produces 1.7 liters of saliva [4] [11].

So many tasks organs-organs, so the body needs water as much as 1.5 to 2 liters or 8 glasses a day in order to work optimally and your metabolism running well and normal. For smokers this amount must be increased by half. Drink sufficient pure water every day is necessary to replace the fluid that is removed from the body through urine, perspiration, respiration, and secretion. When the water in the blood vessels enough (the hydration status of both), the viscosity of blood will be good and circulation more smoothly secretion smoothly and substances that must be disposed of (toxic) will be easily carried away through organ secretions, so that the heart's workload lighter thereby blood pressure will remain normal. Conversely when the body is deprived of 
fluid (dehydration), then the blood viscosity increases, to keep the circulation of cardio function will work harder, so that the blood pressure will increase [12].

In people with heart and kidneys healthy drinking lots of water will not be bad because it is secreted in the form of urine, sweat and water vapor. But instead on people who are not healthy heart and kidneys will cause over-hydration that made the work of the heart and in the case of weight can result in death.

In terms of health sciences water has a function very much. Among the water serves as to maintain freshness, remove toxins in the body and also helps digestion. Besides, water has another benefit that is very good for human health, maintaining fitness, improving blood circulation, heart healthy, give the effect of relaxation, beauty care, and for fertility [12].

The author's experience in the field in general consumption of drinking water in the community do not pay attention to the needs of at least 8 glasses per day. Especially in cool climates such as in Bandung, people tend to drink less than 8 cups, as if drinking more will give a diuretic effect, so they are not uncomfortable frequent urination/urinary. The risk of lack of drinking water consumption will be interference or kidney and cardiovascular disease, including hypertension [13].

The results of the data assessment community in the village of Padjadjaran Bandung that groups of teens to the elderly most have unhealthy habits that did not exercise regularly, eat less vegetables and fruit. As well as the male sex mostly smoke and drink coffee.

Based on the above phenomenon, the author is interested in studying "The contribution of drinking water and other factors in the prevention of hypertension in urban village Puskesmas working area Pasirkaliki Padjadjaran Bandung”.

\section{Materials and Methods}

The study design was a case control with a population of older age groups to pre elderly, aged between 30 - 59 years, is still productive/A healthy daily activities independently. The place of research in the area of the village Padjadjaran Bandung, month study period from July to September 2013. The study was conducted after obtaining ethical approval from the local Ethics Committee (ethical clearance attached).

Research samples:

Samples as is the case group with hypertension were taken from reports of members in Posbindu PTM in the village Pajajaran appropriate inclusion criteria set researcher. Control group is people who do not have hypertension (healthy people) with similar characteristics to the case (matching) in terms of age, gender and the environment.

The number of samples in this study 78 cases and 78 controls so that a total of 156 respondents. Selection of cases and controls were taken from the records Posbindu PTM cadres who meet the inclusion criteria:

1) Age 30 - 59 years.

2) Still can move independently everyday/work.

3) Can communicate verbally.

4) Not being pregnant.

5) Do not suffer from DM.

6) Not suffer from kidney failure.

Data collection habit of drinking water and other factors conducted by interview using a questionnaire. Question drinking water include:

1) Characteristics of respondents (name, age, gender, occupation).

2) Ability to drink since before the diagnosis of hypertension in the case group while the control group asked the habit of drinking at a young age. The question is (the amount of pure water you drink in a day, in addition to water clear whether drinking coffee, drinking tea when drinking how many glasses, whether eating vegetables fry, when eating how much, if eating fruit, when eaten how many fruits are eaten.

3) The other question is the habit of smoking and exercise habits from a young age (before the diagnosis of hypertension in the case group).

Interviews were conducted in the homes of respondents for 15 - 20 minutes with the situation and kinship. Interviews were conducted by 10 health volunteers have been trained. Before conducting the interview the interviewer gives an explanation and asked for consent (informed consent).

Data analysis was performed three stages; univariate first to see the proportion of each variable studied based 
categorization. Then do the bivariate analysis with chi square, odds ratios and logistic regression for multivariate analysis.

\section{Results and Discussion}

\subsection{Results of Univariate Analysis}

It can be seen in Table 1 that most of the respondents were female and the majority of respondents did not work.

It can be seen in Table 2. The results of the univariate analysis of respondents who drink water 6 or more cups of $50.6 \%$, which is drink coffee every day $42.3 \%$, to eat fruit every day $93.6 \%$, to eat vegetables every day $99.4 \%$, respondents who have a habit of smoking $87.2 \%$, almost entirely habit of sports do not exercise.

\subsection{The Results of the Analysis Bivariat}

Table 3 shows the $75.6 \%$ in the case group before being diagnosed with hypertension have the habit of drinking water is less than 6 cups per day, while the control group of $76.9 \%$ drinking at least 6 glasses of water per day. Chi-square test results showed no significant relationship habit of drinking water to the prevention of hypertension $(\mathrm{Pv}=0.000)$. Categorized less when respondents drinking water is less than 6 cups per day, whereas if the respondent is categorized adequate drinking water more than 6 cups per day.

Table 1. Characteristics of respondents (N: 156).

\begin{tabular}{ccc}
\hline No & Variabel & Number \\
\hline & Gender & \\
Male & $64(41.02 \%)$ \\
Female & $92(58.98 \%)$ \\
& Job & \\
& work & $55(35.25 \%)$ \\
& No & $101(64.75 \%)$ \\
& Education & \\
& Primary school & $75(48.00 \%)$ \\
& Secondary school & $65(41.70 \%)$ \\
& University/college & $16(10.30 \%)$ \\
\hline
\end{tabular}

Table 2. Habit of Drinking water, coffee, eat vegetables and fruit, smoking and exercise (N; 156).

\begin{tabular}{|c|c|c|}
\hline No & Variabel & Number \\
\hline 1 & $\begin{array}{l}\text { Habits drinking water } \\
\text { Good/adequate } \\
\text { Less }\end{array}$ & $\begin{array}{l}79(50.6 \%) \\
77(49.4 \%)\end{array}$ \\
\hline 2 & $\begin{array}{l}\text { Coffee drinking habits } \\
\text { Drink } \\
\text { No }\end{array}$ & $\begin{array}{l}66(42.3 \%) \\
90(57.7 \%)\end{array}$ \\
\hline 3 & $\begin{array}{c}\text { Fruit eating habits every day } \\
\text { Eat } \\
\text { No }\end{array}$ & $\begin{array}{l}146(93.6 \%) \\
10(6.4 \%)\end{array}$ \\
\hline 4 & $\begin{array}{l}\text { Vegetable eating habits every day } \\
\text { Eat } \\
\text { No }\end{array}$ & $\begin{array}{c}155(99.4 \%) \\
1(0.6 \%)\end{array}$ \\
\hline 5 & $\begin{array}{l}\text { Smoking habit } \\
\text { Smoke } \\
\text { No }\end{array}$ & $\begin{array}{c}136(87.2 \%) \\
20(12.8 \%)\end{array}$ \\
\hline 6 & $\begin{array}{l}\text { Sports toxicity } \\
\text { Sport } \\
\text { No }\end{array}$ & $\begin{array}{c}6(3.8 \%) \\
150(96.2 \%)\end{array}$ \\
\hline
\end{tabular}


Table 3. Contributions habit of drinking water to the prevention of hypertension $(\mathrm{N} ; 156)$.

\begin{tabular}{ccccc}
\hline Categories & Control & Case & Number & p value \\
\hline Less & $18(23.1)$ & $59(75.6)$ & $77(49.4)$ & 0.000 \\
Adequate & $60(76.9)$ & $19(24.4)$ & $79(50.6)$ & \\
& $78(100)$ & $78(100)$ & $156(100)$ & \\
\hline
\end{tabular}

In Table 4 it can be seen that $52.6 \%$ of those cases have a habit of drinking coffee every day, whereas $67.9 \%$ in the control group did not have the habit of drinking coffee. Statistical test results there is a relationship habitual coffee consumption and hypertension $(\mathrm{Pv}=0.015)$.

In Table 5 shows that $83.3 \%$ of those cases do not have the habit of smoking, and $91.0 \%$ in the control group did not have the habit of smoking. Statistical test results there is no relationship of smoking habits with hypertension $(\mathrm{Pv}=0.23)$.

Table 6 shows the $92.3 \%$ in the case group before being diagnosed with hypertension have a habit of eating fruit, and $94.9 \%$ in the control group also had a habit of eating fruit every day. Chi-square test results showed no significant relationship with the habit of eating fruit prevention of hypertension $(\mathrm{Pv}=0.74)$.

Table 7 shows the $98.7 \%$ in the case group before being diagnosed with hypertension have a habit of eating vegetables every day, and in the control group $100 \%$ in the habit of eating vegetables every day. Chi-square test results showed no significant relationship habit of drinking water to the prevention of hypertension $(\mathrm{Pv}=1.00)$.

Table 8 shows $96.2 \%$ in the case group before being diagnosed with hypertension unusual exercise, and the control group $96.2 \%$ is also not in the habit of exercise. Chi-square test results showed no significant relationship with exercise habits prevention of hypertension $(\mathrm{Pv}=1.00)$.

\subsection{The Results of Multivariate Analysis}

Table 9 shows all the independent variables that are thought to contribute to the prevention of hypertension, after statistically tested was only one variable that contributes to that the habit of drinking water. People who drink water at least 4 times likely to prevent hypertension (95\% CI: 0.044 to 0.217 ) after controlling variables drinking coffee and smoking. Variable habit of drinking water is the most dominant contributing to the prevention of hypertension.

\section{Discussion}

\subsection{Drinking Ordinary Water}

Drinking everyone is different, it is influenced by the family environment in childhood. When the family since childhood to drink tea then during the subsequent development likely to rarely or never drink water. Indonesian society used when there are guests who visited the house, feel more comfortable or awake feelings when giving drink tea, coffee, milk to his guest. Disebagian public opinion used to be that families who only drink water that poor families or poor. Families who used to drink tea, coffee, milk, syrup, carbonated drinks are considered a respectable family or families are. Gradually the people of Indonesia berubahh after getting information that the drinking water is healthier than drinking tea, coffee or soft drinks.

The results showed $50.6 \%$ of drinking water at least 6 glasses per day. This illustrates that the preferences of the individual against an'll beat his common sense, especially when you feel nothing for him [14]. This means that even if people already know the benefits of water for health but when happy and feel mennimbulkan serious health problems as a result of drinking coffee or sweet tea or soft drinks will continue to give priority to his favorite drink.

\subsection{Other Factors (Drinking Coffee, Smoking, Eating Vegetables and Fruits and Sports)}

Drinking coffee when it is customary to be tasted nothing is lost if they do not do it, even among smokers do not feel complete without a cup of coffee on the sidelines sucking on his cigarette. Drinking three cups of coffee a day is not associated with the incidence of hypertension. This is interpreted by people with drinking 3 cups of coffee a day can prevent heart disease and hypertension [10].

In this study, drinking coffee associated with hypertension $(\mathrm{Pv}=0.015)$. The author still believes that drinking 
Table 4. Contributions drinking coffee on hypertension prevention $(\mathrm{N}=156)$.

\begin{tabular}{ccccc}
\hline Categories & Control & Case & Number & p value \\
\hline No & $53(67.9)$ & $37(47.4)$ & $90(57.7)$ & 0.015 \\
Drinking coffee & $25(32.1)$ & $41(52.6)$ & $66(42.3)$ & \\
& $78(100)$ & $78(100)$ & $156(100)$ & \\
\hline
\end{tabular}

Table 5. Contributions habit of smoking on hypertension prevention.

\begin{tabular}{ccccc}
\hline Categories & Control & Case & Number & p value \\
\hline No & $71(91.0)$ & $65(83.3)$ & $136(87.2)$ & 0.23 \\
Smoke & $7(9.0)$ & $13(16.7)$ & $20(12.8)$ & \\
& $78(100)$ & $78(100)$ & $156(100)$ & \\
\hline
\end{tabular}

Table 6. Contributions habit of eating fruit every day to the prevention of hypertension.

\begin{tabular}{ccccc}
\hline Categories & Control & Case & Number & p value \\
\hline No & $4(5.1)$ & $6(7.7)$ & $10(6.4)$ & 0.74 \\
Eat & $74(94.9)$ & $72(92.3)$ & $146(93.6)$ & \\
& $78(100)$ & $78(100)$ & $156(100)$ & \\
\hline
\end{tabular}

Table 7. Contributions habit of eating vegetables every day to the prevention of hypertension.

\begin{tabular}{ccccc}
\hline Categories & Control & Case & Number & p value \\
\hline No & $0(0.0)$ & $1(1.3)$ & $1(0.6)$ & 1.00 \\
Eat & $78(100)$ & $77(98.7)$ & $155(99.4)$ & \\
& $78(100)$ & $78(100)$ & $156(100)$ & \\
\hline
\end{tabular}

Table 8. Contributions habit of physical activity/exercise on the prevention of hypertension.

\begin{tabular}{ccccc}
\hline Categories & Control & Case & Number & pvalue \\
\hline No & $75(96.2)$ & $75(96.2)$ & $150(96.2)$ & 1.000 \\
Sport & $3(3.8)$ & $3(3.8)$ & $6(3.8)$ & \\
& $78(100)$ & $78(100)$ & $156(100)$ & \\
\hline
\end{tabular}

Table 9. Results of multivariate analysis drinking water, drinking coffee and smoking.

\begin{tabular}{ccccc}
\hline Variabel & B & P Wald & OR & $95 \%$ CI \\
\hline Water & -2.322 & 32.979 & & $0.044-0.217$ \\
Coffee & -0.289 & 0.503 & 4.026 & \\
smoking & -0.350 & 0.346 & & \\
\multicolumn{2}{c}{- Plog likelihood $=170.21$} & $\mathrm{G}=46.040$ &
\end{tabular}

coffee may increase the risk of hypertension and heart disease, because it contains caffeine in coffee can stimulate or improve the work of the heart, so that when used to drink coffee heart is always stimulated to work constantly in a high speed.

Smoke more disadvantages than good. In each pack of cigarettes and cigarette advertising has been written Smoking raises risk of heart disease and cancer and threaten the health of the fetus in the womb of his mother. In this study, the majority (87.2\%) of respondents have poisoned smoke. Maybe it is not able to read the writing in ads or warnings on cigarette packs, but they are still healthy despite the smoke.

The habit of eating fruits and vegetables is already a lot better inform the public through counseling directly or indirectly such as leaflets or brochures even through print and electronic media. In this study, nearly all res- 
pondents had to eat vegetables and fruit every day. But when viewed adequacy was inadequate. Eat vegetables and fruit for adults and the elderly is recommended at least five servings a day. Eat vegetables and fruits should be encouraged to fulfill their diverse nutrients it contains, for each vegetable contains nutrients (vitamin and minerals of different type and levels).

The habit of regular exercise, programmed in sufficient quantities and intensity will increase resilience and level of fitness. Exercise will increase to stress, sufficient exercise in the dose and intensity will maintain a normal blood pressure. In this study, nearly all respondents do not have the habit of exercise. Many people assume that when you're doing a lot of physical activity at home is tantamount to exercising. Opinion is not entirely true, because there are the stages began to warm up exercise, core drills and cooling. When the intensity of physical activity at home and measuring enough, at the beginning as there pemnasan activities and ending with relaxation can be considered a good sport, but if it is not measured can not be considered equal [15]. The results of multivariate analysis showed that drinking water is the most dominant factor contribution the prevention of hypertension.

\subsection{The Contribution of Drinking Water to the Prevention of Hypertension}

Some writings convey the benefits of drinking enough water for good health, including the digestive, cardiovascular health, facilitate the disposal of substances that are toxic, beneficial to the health of the skin, giving a relaxing effect [10]. The results showed the habit of drinking water contribute to the prevention of hypertension $(\mathrm{Pv}=0.000)$. Diabsorsi drink of water gets into every cell of the body to be a catalyst in metabolic processes, improving the transportation system, accelerate the process of filtration, reabsorption in the glomerulus, accelerate the process excretion of metabolic waste and toxic substances berrsifat. Thus the water helps maintain the optimization of functions of each organ of the body, including the cardiovascular system, so that by drinking enough water will prevent the incidence of hypertension.

\subsection{Contributions of Other Factors That Contribute to Prevention of Hypertension}

Other factors studied are expected to contribute to the prevention of hypertension was not provable. Some fruits are often consumed by people of Indonesia such as papaya, banana, star fruit, watermelon, melon, and of the types of vegetables such as; cucumbers, and tomatoes, contain vitamins and minerals that can lower blood pressure. In this study, nearly all respondents eat vegetables and fruit both case and control groups, but when viewed in terms of the adequacy of five servings per day could be categorized still lacking. Eat vegetables mostly only 1 - 2 bowl of fruit and bananas, papaya or melon or watermelon just one piece a day. Besides adequacy fruit eating habits are mostly done as an adult even after suffering from hypertension in the case group.

Habits olaraga in the case group and the control group did not differ due almost entirely not do sports. In research Arsdiani (2006) in Semarang proved that exercise done regularly can maintain a normal blood pressure [9].

\subsection{The Most Dominant Factor Contributing to the Prevention of Hypertension}

The most dominant factor contributing to the prevention of hypertension in this study was poisoned drinking water. The same total daily fluid intake berkonribusi to the prevention of hypertension. The definition of total daily fluid intake is the amount of intake in the form; drink water, drink coffee, eat vegetables and fruit every day added for each individual/respondent, then the chi square test. Meanwhile, when viewed by the type of fluid you drink each day separately (drinking water, drinking coffee, drinking tea, eating vegetables and fruit) then conducted multivariate test, and the results of multivariate analysis showed that drinking water is the most dominant factor contribution the prevention of hypertension.

\section{Conclusions and Suggestions}

\subsection{Conclusions}

The conclusions that can be delivered from this study are:

1) Water drinking habit contributes to the prevention of hypertension in village Padjadjaran Bandung. 
2) Factor of drinking water is the most dominant factor contributing to the prevention of hypertension in urban village Puskesmas Pasirkaliki Padjadjaran Bandung.

\subsection{Suggestions}

1) For Paramedic

At each hypertension prevention outreach activities both in the general public or specific groups of school children health officials emphasize that children and people who are still healthy to get enough water to drink at least 6 cups $(1500 \mathrm{ml})$ per day.

2) For the Community

At the public or any family members who are still healthy in order to get used to drink water at least 6 cups $(1500 \mathrm{ml})$ per day. And for those who are already sick angggotanya hypertension, heart disease, kidney disease so that drinking water adapted to his health condition.

\section{Acknowledgements}

1) Thanks to the Director of Health Polytechnic Bandung which have sponsored this research.

2) Thanks to the Chief Medical Officer and the head of Puskesmas Pasirkaliki Bandung, which has given permission to study in the districts of Cicendo.

\section{References}

[1] Riskesdas (2010) The Results of the Health Research Ministery of Health RI 2010. Balitbangkes Ministery of Health Republik Indonesia.

[2] Bustan, M.N. (2007) Epidemiology of Non-Communicable Diseases. PT Rineka Reserved, Jakarta.

[3] Manik, M.E. (2012) Factors Associated with Hypertension in the Elderly Elderly Puskesmas Posyandu Parsoburan Siantar Marihat Pematangsiantar District of the Year 2011.

[4] (1998) Textbook of Cardiology, Faculty of Medicine, School of Medicine, University of Indonesia, Jakarta.

[5] Martiani, A. and Lelyana, R. (2012) Hypertension Risk Factors Evaluated on Ability Drink Coffee. Journal of Nutrition College, 1, 470-485.

[6] Ministery of Health RI (2003) Surveillance Epidemiology Practical Guide (PEP). DG PPM \& PL, R.I. Health Department, Jakarta, Edition 1.

[7] Widyastuti (2004) Relationship Indicators Obesity with Hypertension the Woman, Diponegoro University.

[8] Jamila, W.F. (2009) Relationship between Job Stress with Keadian Hypertension in Workers Brokerage Company (Case Study in Indonesia Futures PT. Russley Cab. Jember).

[9] Syatria, A. (2006) Effects of Sports Programmatic against Blood Pressure at the Faculty of Medicine, University of Diponegoro. The Following Extracurricular Basketball, Undip, 2007.

[10] Acin, B. (2010) Effect of Water Treatment to Decrease Blood Pressure in Hypertension Patients with Moderate Degree in Puskesmas Antapani Bandung Indonesia. Thesis, Nursing Departement Dharma Husada Bandung.

[11] Maryati, S., et al. (2007) Biology to High School Class XI. Jakarta: Gelora Aksara Pratama. Erlangga.

[12] John (2011) Articles Health; Benefits of Water for Healthy Body.

[13] Suheti, T. (2012). Early Detection Cholesterol, Hypertension and Stroke. Millestone.

[14] Sinaga, E.S. (2012) Characteristics of Patients with Hypertension Treated in Hospital Inpatient Vita Insani Pematangsiantar Year 2010-2011.

[15] Nurhasan (2002) Service Medical Standards. Executive Board of the Indonesian Doctors Association, 3rd Edition. 